Original Article

\title{
Hyperthermic effects of hand bathing: benefits of incorporating finger flexion-extension exercise
}

\author{
Tadasu Ohshige, RPT, PhD ${ }^{1 *}$, Akiniko Ohwatashi, RPT, PhD ${ }^{1)}$, Ryoji Kiyama, RPT, PhD $^{1)}$, \\ HirOAKI Nishi, RPT ${ }^{2}$, AKIHISA TAKAMORI, RPT ${ }^{3)}$ \\ 1) Course of Physical Therapy, School of Health Sciences, Faculty of Medicine, Kagoshima University: \\ 8-35-1 Sakuragaoka, Kagoshima 890-8544, Japan \\ 2) Yonemori Hospital, Japan \\ 3) Sendai Medical Association Hospital, Japan
}

\begin{abstract}
Purpose] The purpose of our study was to compare the effects of hand bathing using plain water and water supplemented with inorganic salt and carbonated gas and to assess the hyperthermic effects of performing finger flexion-extension exercise while bathing in water with carbonated gas and inorganic salt and without water. [Subjects and Methods] Sixteen healthy, young males were subjected to plain water bathing, $\mathrm{CO}_{2}$ bathing, kineto- $\mathrm{CO}_{2}$ bathing, or no bathing. $\mathrm{CO}_{2}$ bathing involved bathing in a solution of artificial bath additives including inorganic salts and carbon dioxide. Partial bathing of the hand was implemented for 20 minutes at $41{ }^{\circ} \mathrm{C}$. The concentration of carbonic gas was set at $33 \mathrm{ppm}$. In the kineto- $\mathrm{CO}_{2}$ bathing condition, finger flexion-extension exercise was performed at 60 laps per minute in the same solution used in $\mathrm{CO}_{2}$ bathing. The control group engaged in the same exercise as those in the kineto- $\mathrm{CO}_{2}$ bathing group, but without bathing. [Results] A significant increase in deep-body temperature was observed in the $\mathrm{CO}_{2}$ bathing and kineto- $\mathrm{CO}_{2}$ bathing conditions compared with both the plain water bathing and control condition. [Conclusion] Significantly heightened hyperthermic effects were observed when finger flexion-extension exercise was performed during $\mathrm{CO}_{2}$ bathing.

Key words: Hyperthermia, $\mathrm{CO}_{2}$ bathing, Flexion-extension exercise
\end{abstract}

(This article was submitted Aug. 4, 2015, and was accepted Sep. 17, 2015)

\section{INTRODUCTION}

Tanaka $^{1)}$ recommends partial leg bathing because this bathing method can induce hyperthermic effects all over the body while imposing a minimum load. Furthermore, partial leg bathing is more practical: it can be implemented far more easily than full-body bathing. Partial leg bathing can ease pain or stiffness through increased vascular flow in the region induced by topically expanded arteriovenous vessels. According to Tanaka ${ }^{1}$, these favorable effects are based on the topical supply of oxygen and nutrients as well as the washout of carbon dioxide, lactic acid, and substances responsible for causing inflammation and pain. Partial bathing, such as leg bathing or hand bathing, can enhance systematic circulation through the entire body. Topically captured heat from the blood will circulate all over the body and increase the deep-body temperature by $0.2{ }^{\circ} \mathrm{C}$ to $0.3^{\circ} \mathrm{C}^{3)}$, if given enough time. However, to the best of our knowledge, no study has comprehensively investigated the hyperthermic effects of hand bathing. Therefore, to identify the additional

*Corresponding author. Tadasu Ohshige (E-mail: ohshige@ health.nop.kagoshima-u.ac.jp)

C2015 The Society of Physical Therapy Science. Published by IPEC Inc. This is an open-access article distributed under the terms of the Creative Commons Attribution Non-Commercial No Derivatives (by-ncnd) License $<$ http://creativecommons.org/licenses/by-nc-nd/3.0/> . benefits of partial bathing beyond those recognized in our previous study ${ }^{4}$, the effects of hand bathing using plain water and water supplemented with inorganic salt and carbonated gas were assessed and compared. We also attempted to increase the effects of warm bathing by introducing finger flexion-extension exercises in the water with inorganic salt and carbonated gas.

\section{SUBJECTS AND METHODS}

Sixteen healthy, young male subjects (mean age \pm standard deviation [SD], $22.5 \pm 2.6$ years) were recruited. According to Horikiri ${ }^{5}$, the deep-body temperature increases from $0.7^{\circ} \mathrm{C}$ to $1.0^{\circ} \mathrm{C}$ after full-body bathing at $41{ }^{\circ} \mathrm{C}$ for 10 minutes. The optimal temperature at which a thermal effect is elicited during warm-water bathing is between $38^{\circ} \mathrm{C}$ and $41{ }^{\circ} \mathrm{C}$. Water temperatures higher than $42{ }^{\circ} \mathrm{C}$ are inappropriate because heat stimulation can lead to sympathicotonia ${ }^{6}$. Therefore, the water temperature was set at $41^{\circ} \mathrm{C}$, and the duration of bathing was set at 20 minutes. In order to maintain a consistent environment, the room temperature was fixed at $19.0^{\circ} \mathrm{C}$.

Hand bathing constituted the following two conditions: plain-water bathing and bathing in a solution of artificial bath additives including inorganic salts and carbon dioxide $\left(\mathrm{CO}_{2}\right.$ bathing). A bath additive product named "Kikiyu", manufactured by Bathclin Co., Ltd., was added into the water used for $\mathrm{CO}_{2}$ bathing. According to the study by 
Watanabe et al. ${ }^{7}$, $30 \mathrm{~g}$ of Kikiyu bath additive was added per $200 \mathrm{~L}$ of water. The stirring rate for carbon dioxide was $33 \mathrm{ppm}$. In addition to plain water bathing and $\mathrm{CO}_{2}$ bathing, we also conducted kineto- $\mathrm{CO}_{2}$ bathing, which involved flexion-extension exercise of the metacarpophalangeal joints, proximal interphalangeal joints, and distal interphalangeal joints in the same solution used in the $\mathrm{CO}_{2}$ bathing condition. This flexion-extension exercise was performed at 60 laps per minute using all joints of the fingers simultaneously. Finally, in the control condition, the finger flexion-extension exercise was performed outside of water.

The region of the hand involved in the bathing was the area covering one-third of the right forearm. Subjects participated in either hand bathing or control group conditions for 20 minutes after resting by sitting quietly on a chair. Subjects were randomly assigned to the hand bathing or control group conditions on different dates. The water temperature for hand bathing was established using the CM-210 (CM210 Terumo Co., Ltd., Tokyo, Japan) and maintained with SBH-802FVII (SBH-802FVII Kumagai Electric Co., Ltd., Osaka, Japan).

Measurements included heart rate, blood pressure, deepbody temperature, skin blood flow, superficial temperature, and subjective heat perception. Measurements were taken 20 minutes after hand bathing during rest. The heart rate was measured with the BSM-2401 (BSM-2401 Nihon Kohden Co., Ltd., Tokyo, Japan). Both systolic blood pressure and diastolic blood pressure were measured at the left upper arm with a digital automatic sphygmomanometer (HEM-770A OMRON Co., Ltd., Kyoto, Japan). Deep-body temperature was measured on the basis of the sublingual temperature using the CM-210. The ALF21N (ALF21N ADVANCE Co., Ltd, Tokyo, Japan) was adapted to measure skin blood flow at the right upper forearm. Superficial temperature was measured at the left hallux using the THERMO-HUNTER HR-1(THERMO-HUNTER HR-1 OPTEX Co., Ltd., Shiga, Japan). The Borg scale ratings of perceived exertion were modified to measure subjective heat perception (Table 1). The study design was approved by the School of Health Sciences Faculty of Medicine Kagoshima University Ethics Committee (No. 318).

All subjects signed a consent form after being informed of the study purpose, content, and all risks involved. All statistical calculations were performed using SPSS ver.23 (SPSS Inc., Chicago, IL, USA) software. The Shapiro-Wilk test was used to confirm normal distribution of data. If a significant difference was detected after normal distribution was confirmed at all levels, a multiple comparison test was performed. After confirming a normal distribution with the Shapiro-Wilk test followed by the Mauchly's test of sphericity, one-factor repeated-measure analysis of variance (ANOVA) was conducted. When the results of one-factor repeated-measure ANOVA produced a p-value $<0.05$, a Bonferroni's multiple comparison test was performed. When a normal distribution was not confirmed with the ShapiroWilk test, the Friedman's test was conducted. If the results of the Friedman's test produced a p-value $<0.05$, the multiple comparison with Wilcoxon's test was performed after adjusting the values with the Bonferroni multiple hypothesis test correction.
Table 1. Subjective heat perception

\begin{tabular}{lc}
\hline Extremely hot & 10 \\
& 9 \\
Very hot & 8 \\
& 7 \\
Hot & 6 \\
Slightly hot & 5 \\
Just right (Optimal) & 4 \\
Lukewarm & 3 \\
Very lukewarm & 2 \\
Extremely lukewarm & 1 \\
Don't feel anything & 0.5 \\
\hline The Borg scale ratings of perceived exer- \\
tion (RPT) were modified to assess sub- \\
jective heat tolerance
\end{tabular}

\section{RESULTS}

Post-bath heart rates increased in all four conditions (plain water bathing, $\mathrm{CO}_{2}$ bathing, kineto- $\mathrm{CO}_{2}$ bathing, and control), and the results of the one-way ANOVA demonstrated significant differences $(\mathrm{p}<0.05)$ in pre-bath and post-bath values. The results of the multiple comparison test showed significantly higher $(\mathrm{p}<0.05)$ heart rates after kineto- $\mathrm{CO}_{2}$ bathing than after plain water bathing, $\mathrm{CO}_{2}$ bathing, or the control condition (Table 2). However, the results of the oneway ANOVA were insignificant for systolic blood pressure and diastolic blood pressure (Table 2). Sublingual temperature increased in all four conditions (plain water bathing, $\mathrm{CO}_{2}$ bathing, kineto- $\mathrm{CO}_{2}$ bathing, and control), and the results of the one-way ANOVA demonstrated significant differences $(p<0.05)$ in pre-bath and post-bath values (Table 2$)$. The results of the multiple comparison test for sublingual temperature exhibited significantly higher values $(\mathrm{p}<0.05)$ in the $\mathrm{CO}_{2}$ bathing and kineto- $\mathrm{CO}_{2}$ bathing conditions than in the plain water bathing and control conditions (Table 2).

Skin blood flow increased in all four conditions (plain water bathing, $\mathrm{CO}_{2}$ bathing, kineto- $\mathrm{CO}_{2}$ bathing, and control) in terms of the post-bath values during rest. In particular, the significant difference $(p<0.05)$ in skin blood flow was detected in the conditions where the finger flexion-extension exercise was incorporated (Table 2). These findings suggest that the finger flexion-extension exercise effectively facilitates circulation in the body. An average increase in the superficial temperature of the hallux (by $3.2{ }^{\circ} \mathrm{C}$ to $5.8^{\circ} \mathrm{C}$ ) was observed after hand bathing. Although the results of the one-factor ANOVA for increased superficial temperature of the hallux did not reach statistical significance for the plain water bathing, $\mathrm{CO}_{2}$ bathing, or kineto- $\mathrm{CO}_{2}$ bathing conditions, the highest increase in the temperature $\left(5.8^{\circ} \mathrm{C}\right)$ was detected in the kineto- $\mathrm{CO}_{2}$ bathing condition (Table 2).

Subjects reported a change in their perception of warmth from "lukewarm" to "slightly hot" 20 minutes after the bath. The results of the Friedman's test for perception of warmth showed a significant difference. Subjects who underwent $\mathrm{CO}_{2}$ bathing and kineto- $\mathrm{CO}_{2}$ bathing reported significantly 
Table 2. One-way repeated measures analysis of variance and multiple comparisons for each variable before and after bathing

\begin{tabular}{lcccc}
\hline Experimental variables & $\begin{array}{c}\text { Plain water } \\
\text { bathing }\end{array}$ & $\mathrm{CO}_{2}$ bathing & $\begin{array}{c}\text { Kineto- } \mathrm{CO}_{2} \\
\text { bathing }\end{array}$ & Control group \\
\hline Heart rate $(\mathrm{bpm})$ & $7.0 \pm 5.0^{\mathrm{c}}$ & $7.7 \pm 6.6^{\mathrm{c}}$ & $14.0 \pm 8.0^{\mathrm{abd}}$ & $3.9 \pm 4.5^{\mathrm{c}}$ \\
Systolic blood pressure $(\mathrm{mmHg})$ & $-1.2 \pm 7.8$ & $-0.1 \pm 5.6$ & $3.0 \pm 11.2$ & $-0.1 \pm 3.0$ \\
Diastolic blood pressure $(\mathrm{mmHg})$ & $0.0 \pm 5.6$ & $-1.8 \pm 4.9$ & $5.8 \pm 6.2$ & $4.8 \pm 2.6$ \\
Sublingual temperature $\left({ }^{\circ} \mathrm{C}\right)$ & $2.2 \pm 2.2^{*} 10^{-1 \mathrm{bc}}$ & $3.6 \pm 2.3^{*} 10^{-1 \mathrm{ad}}$ & $4.9 \pm 2.2^{*} 10^{-1 \mathrm{ad}}$ & $0.9 \pm 0.4^{*} 10^{-1 \mathrm{bc}}$ \\
Difference in forearm skin blood flow: after bathing/during rest & $1.2 \pm 0.4^{\mathrm{cd}}$ & $1.2 \pm 0.4^{\mathrm{cd}}$ & $2.4 \pm 0.9^{\mathrm{ab}}$ & $2.3 \pm 0.8^{\mathrm{ab}}$ \\
Superficial temperature of hallux $\left({ }^{\circ} \mathrm{C}\right)$ & $4.3 \pm 1.4$ & $3.2 \pm 1.3$ & $5.8 \pm 1.1$ & \\
Perception of warmth & $2.2 \pm 1.6^{\mathrm{cb}}$ & $3.2 \pm 1.2^{\mathrm{a}}$ & $4.2 \pm 1.5^{\mathrm{a}}$ & \\
\hline
\end{tabular}

${ }^{a}$ Compared to plain water bathing values $(\mathrm{p}<0.05)$

${ }^{\mathrm{b}}$ Compared to $\mathrm{CO}_{2}$ bathing values $(\mathrm{p}<0.05)$

${ }^{\mathrm{c}}$ Compared to Kineto- $\mathrm{CO}_{2}$ bathing values $(\mathrm{p}<0.05)$

$\mathrm{d}$ Compared to control group values $(\mathrm{p}<0.05)$

$* \mathrm{CO}_{2}$ bathing involved bathing in a solution of artificial bath additive including inorganic salts and carbon dioxide

*Kineto- $\mathrm{CO}_{2}$ bathing involved the finger flexion-extension exercise in the same solution used in $\mathrm{CO}_{2}$ bathing

*Control group participated in the same finger flexion-extension exercise outside of water

greater perception of warmth $(\mathrm{p}<0.05)$ than their counterparts in the plain water bathing condition according to the results of the Wilcoxon's test adjusted with the Bonferroni multiple hypothesis test correction (Table 2).

\section{DISCUSSION}

The heart rates increased by approximately $7 \mathrm{bpm}$ in both the plain water bathing and $\mathrm{CO}_{2}$ bathing conditions. The increase in heart rates might be attributed to the inhibition of the parasympathetic nerves ${ }^{8)}$ facilitated by heat-induced vasodilation due to warm water bathing. Compared to the values obtained during rest, the heart rates increased even further by $14 \mathrm{bpm}$ after introducing the finger flexionextension exercise in the $\mathrm{CO}_{2}$ bathing condition. This striking upturn is due to the mental strain imposed by the finger flexion-extension exercise, excitability of the sympathetic neurons mediated by muscle spindles, and the stimulus to the sinus node itself triggered by right atrial dilatation ${ }^{9-11)}$. The effects of warm water bathing may have contributed to the lowering of the diastolic blood pressure. However, no notable differences were detected between plain water bathing and $\mathrm{CO}_{2}$ bathing conditions.

The deep-body temperature increased by only approximately $0.1{ }^{\circ} \mathrm{C}$ in the control group, indicating that the finger flexion-extension exercise alone cannot increase deep-body temperature. The deep-body temperature increased approximately $0.2^{\circ} \mathrm{C}$ in the plain water bathing condition, which was lower than the increase with $\mathrm{CO}_{2}$ bathing $\left(0.3{ }^{\circ} \mathrm{C}\right)$. Thus, these findings suggest that the finger flexion-extension exercise can induce beneficial effects on deep-body temperature only in combination with warm water bathing. The synergistic effects of heat from the $\mathrm{CO}_{2}$ bathing and increased skin blood flow due to the finger flexion-extension exercise contribute to the rise in deep-body temperature.

Tanaka et al. ${ }^{2)}$ state that the chloride capsule created over the surface of the skin along with the mirabilite lead to higher deep-body temperature in $\mathrm{CO}_{2}$ bathing. The results of our study are consistent with those of Tanaka et al. ${ }^{2)}$; similar positive effects concerning deep-body temperature occurred in the $\mathrm{CO}_{2}$ bathing condition. Furthermore, the studies by Nonaka demonstrated that $\mathrm{CO}_{2}$ bathing has the potential to accelerate skeletal muscle regeneration after injury ${ }^{12)}$ by increasing the expression of myogenin ${ }^{13}$. Heat conducted through warm water induces the opening of arteriovenous anastomoses, thereby accelerating skin blood flow. This large volume of heated blood will circulate throughout the body to raise the deep-body temperature. In our study, a significant increase in forearm skin blood flow was demonstrated in the control and kineto- $\mathrm{CO}_{2}$ bathing condition compared with the plain water and $\mathrm{CO}_{2}$ bathing conditions. This is due to the increase in the skin blood flow facilitated by muscle pump effects from the finger flexion-extension exercise.

These synergistic effects of increased skin blood flow and deep-body temperature due to $\mathrm{CO}_{2}$ bathing may have caused the significant increase in deep-body temperature (of approximately $0.5^{\circ} \mathrm{C}$ ) in the kineto- $\mathrm{CO}_{2}$ bathing condition compared with the control condition or the plain water bathing condition. Shimodozono et al. ${ }^{14)}$ demonstrated that warm water bathing significantly decreases muscle rigidity. Thus, it is likely that incorporating exercise into warm water bathing will improve finger mobility. Furthermore, Ueda ${ }^{15}$ ) showed that the concentration of lactic acid in blood significantly decreases after incorporation of exercise during $\mathrm{CO}_{2}$ bathing. Therefore, it is reasonable to expect that exercise during warm water bathing would improve finger mobility and exercise tolerance. In our study, hand bathing successfully increased the superficial temperature of the hallux by $3.2{ }^{\circ} \mathrm{C}$ to $5.8^{\circ} \mathrm{C}$. In particular, the highest increase $\left(5.8^{\circ} \mathrm{C}\right)$ in the superficial temperature of the hallux was detected in the kineto- $\mathrm{CO}_{2}$ bathing condition. Thus, warming the hands in the washroom and engaging in finger flexion-extension exercise could ease the cold feeling in the feet and toes.

Finally, the perception of warmth was significantly heightened in the $\mathrm{CO}_{2}$ bathing and kineto- $\mathrm{CO}_{2}$ bathing conditions compared with during plain water bathing. Subjects reported feeling "slightly hot" in the kineto- $\mathrm{CO}_{2}$ bathing condition. Thus, the results of our study suggest that incorporating finger flexion-extension exercise into hand bathing provides greater perception of warmth even in this type of 
simple partial bathing. Taken together, the accumulating body of evidence from our study highlights the beneficial effects of finger flexion-extension exercise while hand bathing. Incorporating such exercise into hand bathing therapy can increase deep-body temperature, improve finger mobility and exercise tolerance, as well as ease the cold feeling in the feet and toes.

\section{REFERENCES}

1) Tanaka N, Sugimura K, Shimazaki H, et al.: Effects of hot footbath on motor function in healthy volunteer - with special reference for gender difference of foot bath effects-. J Jpn Soc Balneol Climatol Phys Med, 2009, 72 141-147.

2) Tanaka N, Hiyoshi T, Takesako K, et al.: Effects of artificial mineral spring (basukurin) on hemodynamic functions, deep body temperature, autonomic nervous functions and blood gas concentration. J Jpn Soc Balneol Climatol Phys Med, 1987, 50: 187-196.

3) $\mathrm{Xu} \mathrm{FH}$, Ogawa $\mathrm{H}$, Wang $\mathrm{H}$, et al.: Different physiological changes on carbonated localized bathing of hands and feet in healthy males. J Jpn Soc Balneol Climatol Phys Med, 2009, 72: 148-166.

4) Ohshige T, Ohwatashi A, Kiyama R: The varying effects of warm-wate bathing therapies: partial bathing decreases exercise intensity to levels similar to full-body bathing. J Phys Ther Sci, 2015.

5) Horikiri Y, Tanaka N: The application of underwater exercise to circulation. J Clin Rehabil, 1998, 7: 683-687.

6) Hasegawa M: matuzaki A, Andou H: Effect of the depth of the water bath- ing on hemodynamics in patients with myocardial infarction. Ther Res, 1989, 10: 4248-4254

7) Watanabe $S$, Imanishi $N$, Ishizawa $T$, et al.: The effects of bathing with inorganic salts and carbon dioxide on body temperature, systemic circulation, and food ingestion and absorption. J Jpn Soc Balneol Climatol Phys Med, 2006, 69: 167-178

8) Tanaka N, Myata M, Shimodozono M, et al.: Comparative study on the effects of health promotion of single bathing and $200 \mathrm{~m}$ running. J Jpn Soc Balneol Climatol Phys Med, 2011, 74: 263-272.

9) Tanaka N, Kawahira K, Takesako K, et al.: Hypotensive effect of spa therapy in different types of essential hypertension. J Jpn Soc Balneol Climatol Phys Med, 1982, 45: 10-13.

10) Tanaka N, Kawahira K, Takesako K: Spa therapy on cardiovascular diseases. Gen Rehabil, 1989, 17: 581-588.

11) Hiyoshi T, Tanaka N: Jyakunen sportsman no jyomyaku no hassei kijyo ni tsuite [evelopmental mechanism of bradycardia in young athletes]. Jiritsu Shinkei, 1986, 23: 436-440 (in Japanese).

12) Nonaka K, Akiyama J, Tatsuta N, et al.: Carbon dioxide-rich water bathing increases myonuclear number and muscle fiber size in regenerating skeletal muscles. J Phys Ther Sci, 2012, 24: 1295-1298. [CrossRef]

13) Nonaka K, Akiyama J, Tatsuta N, et al.: Carbon dioxide water bathing enhances myogenin but not MyoD protein expression after skeletal muscle injury. J Phys Ther Sci, 2013, 25: 709-711. [Medline] [CrossRef]

14) Shimodozono $M$, Ninomiya $K$, Matsumoto $S$, et al.: Effects of bathing with artificial bath additive including inorganic salts and carbon dioxide on body flexibility, muscle stiffness and subjective feeling of bathing. J Jpn Soc Balneol Climatol Phys Med, 2011, 74: 227-236.

15) Ueda M, Yazaki T: The effects of bathing using a new co2 bath-water generator on changes of blood lactic acid density after exercise. J Jpn Soc Balneol Climatol Phys Med, 2000, 63: 73-78. 